\title{
REVIEWS ON HYCOM AND MYOCEAN WITH FOCUS ON BRAZIL CURRENT SYSTEM, BETWEEN CABO FRIO AND CABO DE SÃO TOMÉ
}

\author{
BOECHAT, A.C.R. ${ }^{1 *} \&$ DA CRUZ, L.M.M. ${ }^{1}$ \\ 1. Prooceano Serviço Oceanográfico e Ambiental Ltda. \\ *Corresponding author: ana.boechat@prooceano.com.br
}

\begin{abstract}
Boechat, A.C.R. ${ }^{1}$ \& Da Cruz, L.M.M. ${ }^{1}$, 2017. Reviews on HYCOM and MyOcean with focus on Brazil current system, between Cabo Frio and Cabo de São Tomé. braz. J. Aquat. Sci. Technol. 19(3). elSSN 1983-9057. DOI: 10.14210/bjast. v19n3. Products of numerical models, such as HYCOM (Hybrid Coordinate Ocean Model) and MyOcean, are widely used in scientific circles. In the present study, these two databases were compared for a radial between Cabo Frio and Cabo de São Tomé, aiming their application for the Brazil Current System. Therefore, this study presents analysis for the percentage of kinetic energy in each longitudinal band of the BC, and also for it volume transport and for it limits depth of occurrence.
\end{abstract}

Keywords: Western boundary current; Numerical model; Kinetic energy; Volume transport.

\section{INTRODUCTION}

Western boundary currents are characterized by intense and well-defined streams flowing on western oceans' edge, especially in regions of shelf break. They are currents that flow from low latitudes, traveling long distances, to colder regions at high latitudes. The western boundary current of the South Atlantic is the Brazil Current (BC), being the object of analysis of this study, specifically its flux between Cabo Frio and Cabo de São Tomé.

The BC, allied to Intermediate Western Boundary Current (IWBC) and Deep Western Boundary Current (DWBC), form a system of western currents, which occupies $3000 \mathrm{~m}$ in the water column. The IWBC is located just below the $\mathrm{CB}$ and flows to north, and then comes the DWBC, flowing to south again (Silveira, 2007). The movement is almost null at depths where reversal flow occurs.

In general, the advent of numerical simulations has emerged to fill certain gaps in the knowledge of ocean circulation. In the present study, it was chosen two different datasets: the HYCOM (Hybrid Coordinate Ocean Model) database and the MyOcean Reanalysis. For each database, results were obtained for a radial situated between Cabo Frio e Cabo de São Tomé.

The HYCOM model is a multi-institutional project sponsored by the National Ocean Partnership Program (NOPP), as part of the U.S. Global Ocean Data Assimilation Experiment (GODAE). It is a hybrid model that uses an isopycnal coordinate system in stratified layers, z Cartesian coordinates in mixed layers and low stratified areas, and sigma layers in regions with lower depths and variable topography (coastal areas) (Bleck, 2002). The data used from HYCOM has a spatial resolution of $1 / 12^{\circ}$.

In contrast, the MyOcean was developed by the European Comission as part of an initiative known as Global Monitoring for Environment and Security (GMES). The numerical ocean model used in MyOcean is the Nucleus for European Models of the Ocean (NEMO), forced by atmospheric fields obtained from the analysis of the European Centre for Medium-Range Weather Forecasts (ECMWF). The NEMO assimilates currents data, surface elevation and SST obtained from satellites, in addition to temperature and salinity obtained in situ (Larnicol et al., 2006). The data used from MyOcean has a spatial resolution of $1 / 4^{\circ}$.

\section{MATERIALS AND METHODS}

Results of zonal $(\mathrm{u})$ and meridional $(\mathrm{v})$ currents were obtained from the databases of HYCOM and MyOcean models. For each database, it was selected a radial between Cabo Frio and Cabo de São Tomé. The HYCOM radial presented a latitude of $22^{\circ} 26^{\prime} 35^{\prime \prime}$, varying from $41^{\circ} 45^{\prime} 36^{\prime \prime} \mathrm{W}$ to $38^{\circ} 28^{\prime} 48^{\prime \prime} \mathrm{W}$, in longitude. For MyOcean, the radial presented a latitude of $22^{\circ} 24^{\prime} 22^{\prime \prime} S$, varying from $41^{\circ} 37^{\prime} 30^{\prime \prime} \mathrm{W}$ and $38^{\circ} 37^{\prime} 30^{\prime \prime} \mathrm{W}$, in longitude. Both radials are presented in Figure 1. The data covers a period from January 2004 to December 2010 , totaling seven years.

Featuring the data described above, the following analyses were made: calculation of the $B C$ and IWBC volume transport; percentage analysis of $B C$ kinetic energy contained in longitudinal pre-established bands; and the analysis of the average depth of $\mathrm{BC}$. For this, the limits of BC and IWBC, both in depth and longitudinally, were defined based on the studies of Lima (1997) and Fragoso (2004). The BC was limited, in depth, from surface to $400 \mathrm{~m}$ and, longitudinally, between the isobaths of 100 and $2000 \mathrm{~m}$. The IWBC was limited, in depth, from 400 to $1500 \mathrm{~m}$ and, longitudinally, between the isobath of $400 \mathrm{~m}$ and $-39,5^{\circ} \mathrm{W}$. 


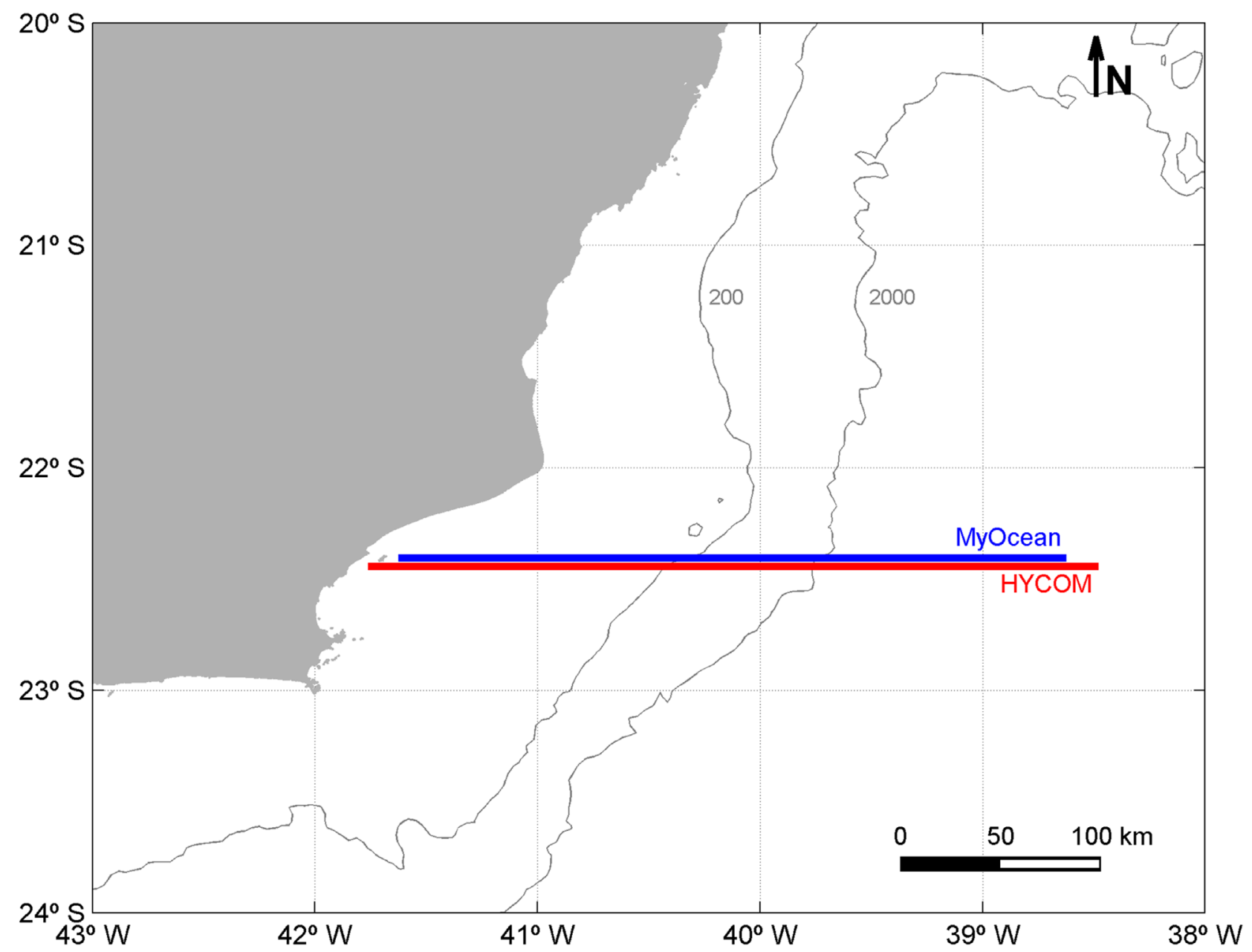

Figure 1 - Radials of HYCOM and MyOcean database used in the present study.

Using the proposed limits, it was calculated the $B C$ and IWBC volume transport. In view of predominance of a meridional transport, the volume transport was calculated as $W=v x S$. Where $W$ is the transport, is the meridional component and is the region area. The transport obtained by HYCOM database was compared to that obtained by MyOcean. This comparison was made using a corrcoef (Correlation Coefficient) function from the toolbox available in Matlab R2007b.

From this analysis, it was obtained a correlation coefficient $(r)$, which is tested in order to obtain its significance $(p)$. If $p$ is a small value, less than 0,05 , the correlation is significant.

The correlation coefficient of two random variables is a measure of their linear dependence, and it can be defined in terms of the covariance of $A$ and $B$ :

$$
\rho(A, B)=\frac{\operatorname{cov}(A, B)}{\sigma_{A} \sigma_{B}}
$$

Where $\sigma_{A}$ and $\sigma_{B}$ are the standard deviation of $A$ and $B$, respectively.
Although it wasn't used the same methodology, it is interesting to compare the volume results obtained in other literature studies. Therefore, it was selected the studies of Lima (1997) and Fragoso (2004).

The percentage of BC kinetic energy was calculated for each isobath band, being: from shoreline to $100 \mathrm{~m}$; from 100 to $1000 \mathrm{~m}$; from 1000 to $2000 \mathrm{~m}$; and from 2000 to $3000 \mathrm{~m}$.

The BC average depth was obtained based on the sign of the meridional current component (v), which reflects the meridional direction of the current flow.

\section{RESULTS}

In Figure 2, is shown a comparison for the BC monthly mean transport between HYCOM and MyOcean databases.

Histograms of monthly mean volume transport obtained for HYCOM and MyOcean (Figure 3) were compared with those obtained by Lima (1997) and Fragoso (2010) (Figure 4). 
CB - HYCOM E MYOCEAN $|r=0.43898| p=2.9515 e-05$

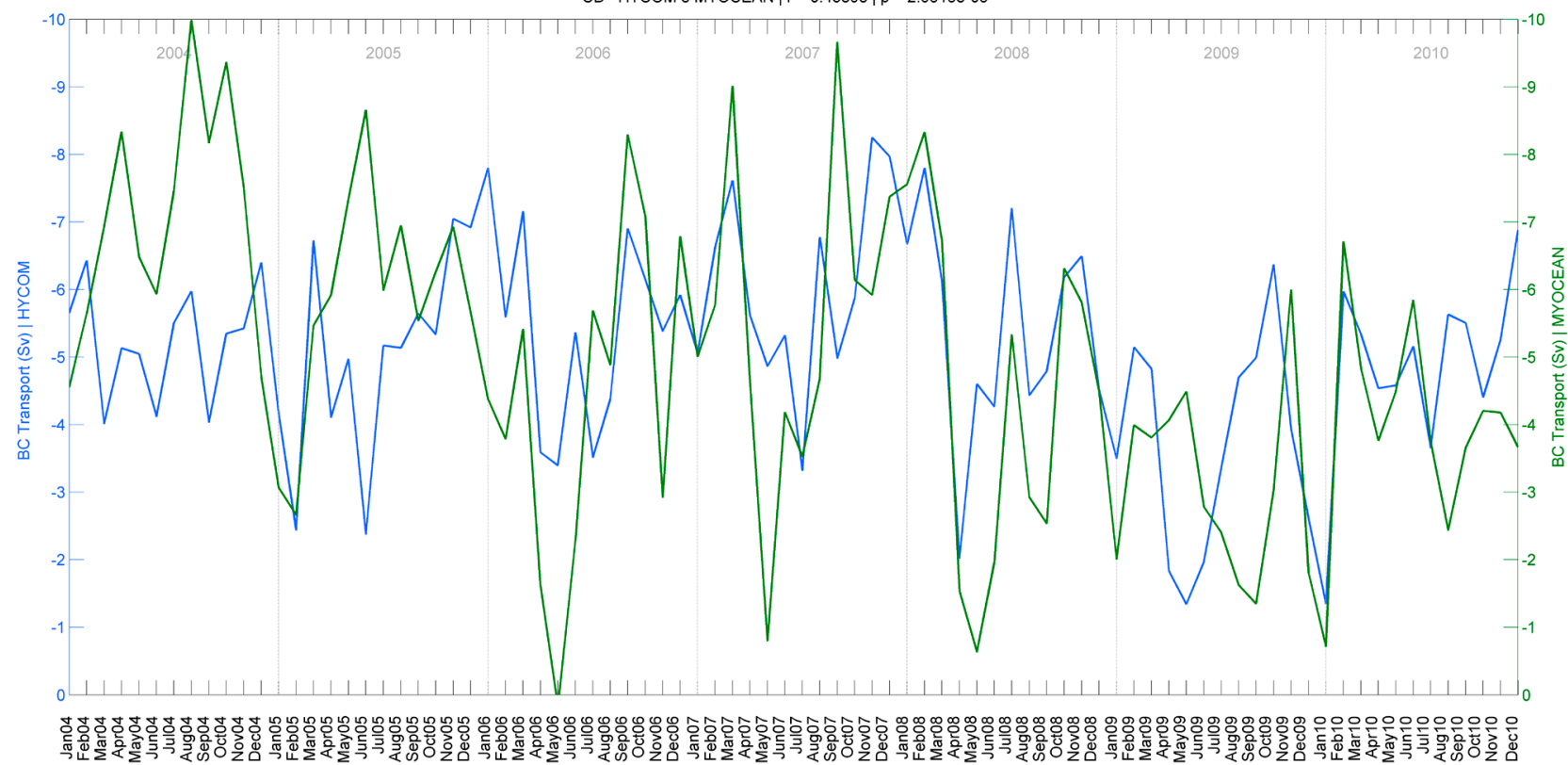

Figure 2 - BC monthly mean transport (Sv) for months analyzed between 2004 and 2010, based on HYCOM (blue) and MyOcean data (green).
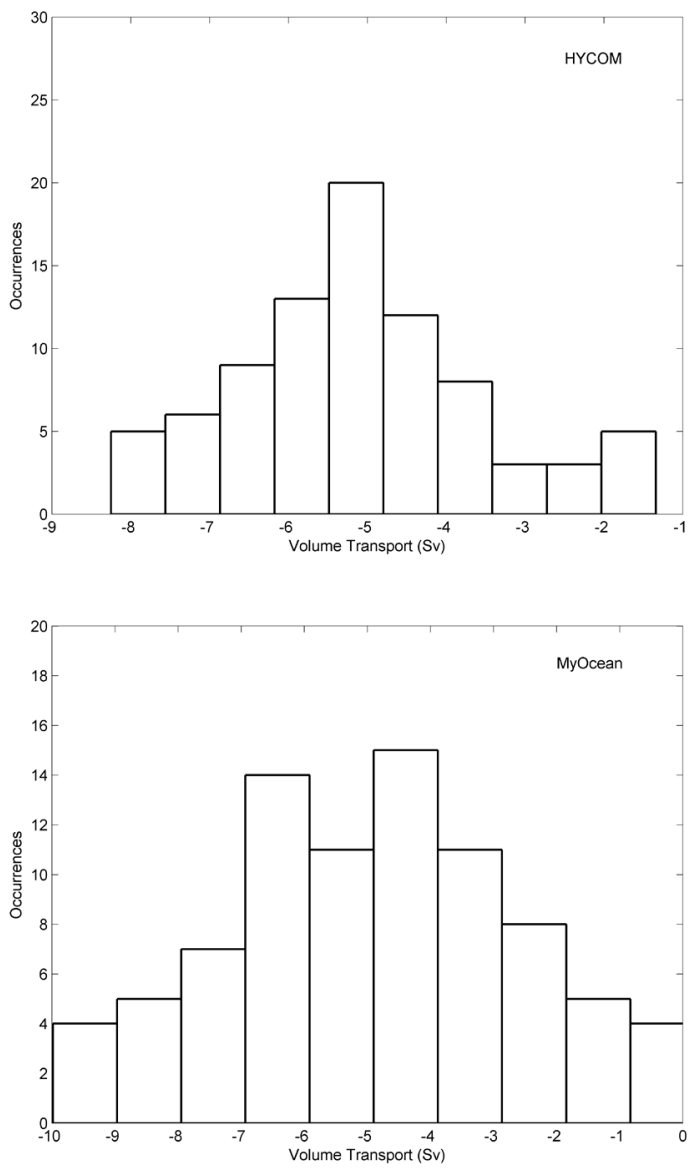

Figure 3 - Histograms of BC volume transport obtained by HYCOM (above panel) and MyOcean (below panel).
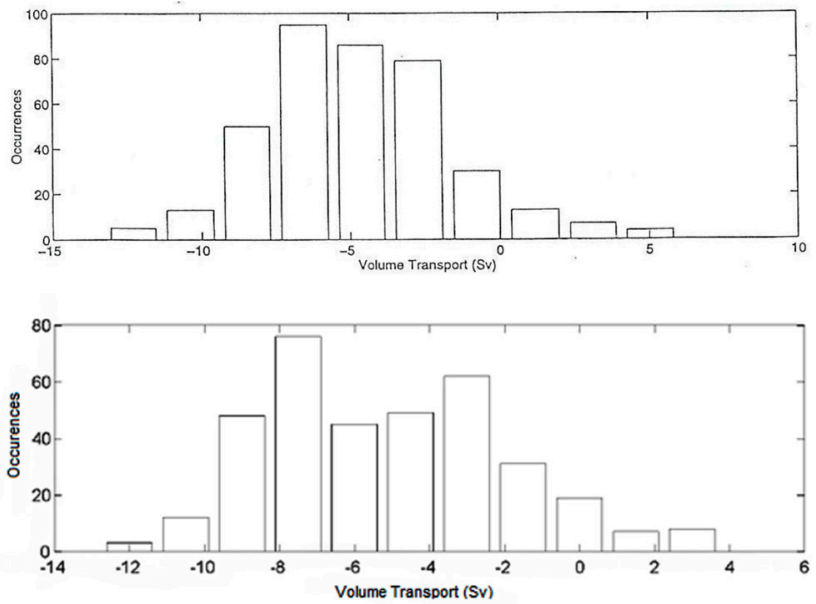

Figure 4 - In the above panel, a histogram of BC volume transport between May 1994 and May 1995, obtained by Lima (1997). In the below panel, a histogram of $\mathrm{BC}$ volume transport obtained for the year of 1999, by Fragoso (2004).

The IWBC transport was also compared with both databases and the results are presented in Figure 5.

With the longitudinal bands described in Materials and Methods, it was also analyzed what is the percentage of mean kinetic energy relative to all times for each of these bands (Figure 6).

Finally, it was analyzed the average depth of BC occurrence considering vertical sections of meridional current component (Figure 7). 
Boechat, A.C.R. \& Cruz, L.M.M., (2017). Current analysis for two different databases in Campos Basin - Brazil.
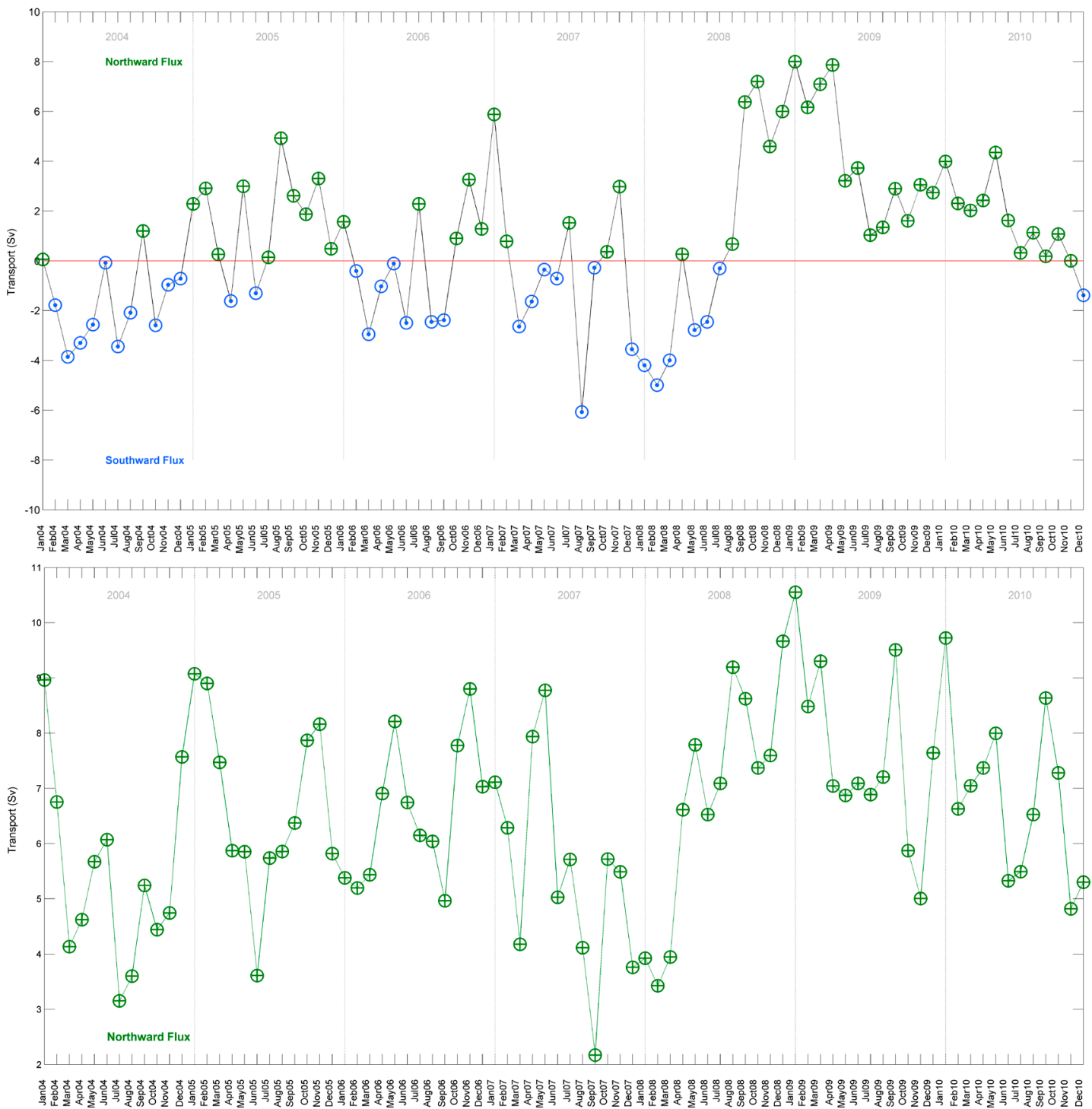

Figure 5 - IWBC monthly mean volume transport (Sv) calculated with HYCOM (panel above) and MyOcean data (panel below). In green, is presented the points where the transport is positive (Northward flux) and, in blue, the points where the transport is negative (Southward flux). The red line indicates where the transport is null.

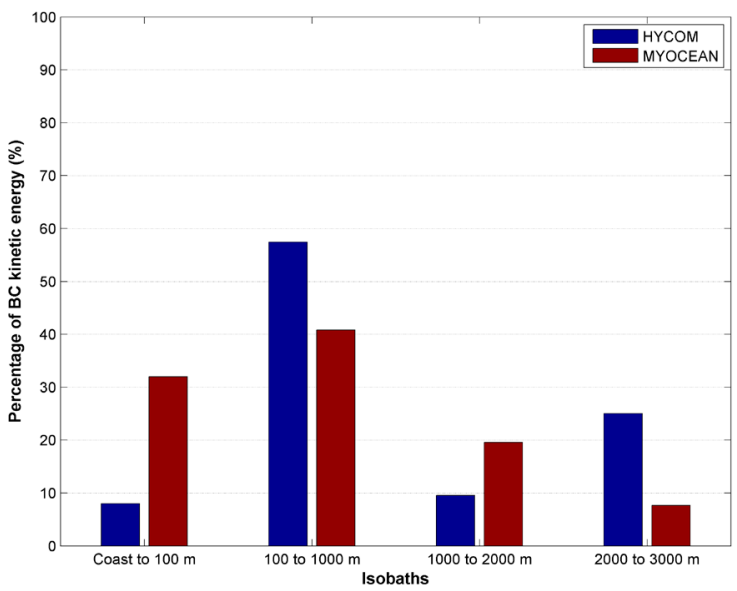

Figure 6 - Percentage of BC kinetic energy found in each isobath band for HYCOM and MyOcean data: from shoreline to $100 \mathrm{~m}$, from 100 to $1000 \mathrm{~m}$, from 1000 to $2000 \mathrm{~m}$ and from 2000 to $3000 \mathrm{~m}$. 

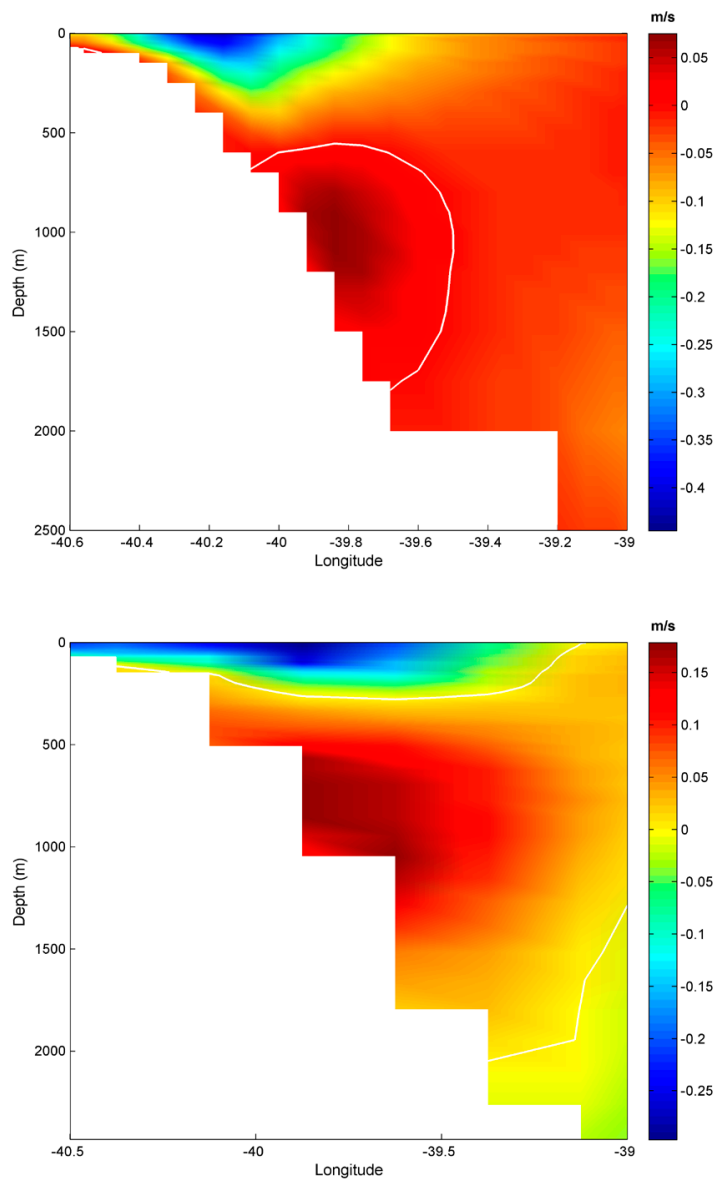

Figure 7 - Vertical section for meridional current component $(\mathrm{m} / \mathrm{s})$ for HYCOM (panel above) and MyOcean (panel below). The white line represents where the meridional component is null, in other words, where the inversion of flux occurs.

\section{DISCUSSION}

The correlation between the two curves (Figure 2) showed values of 0,44 for $r$ and $2,9 \times 10^{-5}$ for $p(p$ $<0,05)$, indicating a significant correlation for the $\mathrm{BC}$ transport.

Lima (1997) has found a mean BC volume transport in Campos Basin of $-5,5 \pm 2,6 \mathrm{~Sv}$, versus $-5,1 \pm$ 3,2 Sv calculated by Fragoso (2004) simulation. This comparison reflects a great concordance: for HYCOM transport, the mean transport was $-5,1 \pm 1,5 \mathrm{~Sv}$, while for MyOcean, it was $-4,9 \pm 2,3 \mathrm{~Sv}$.

For HYCOM database, $60,71 \%$ of IWBC flux was northwards, indicating that over $50 \%$ of the flux flows to north. In other hand, for MyOcean database, $100 \%$ of the transport analyzed was positive (flows northwards), what is expected for the region. For the curves correlation, it was obtained a value of 0,63 for $r$ and of $1,3 \times 10^{-10}$ for $p(p<0,05)$, indicating a significant correlation between the IWBC transport data.
In general, it is noticed that the range correspondent to isobaths 100 to $1000 \mathrm{~m}$ represents the highest percentage of kinetic energy (average higher than $40 \%$ ).

The depth where the component is null indicates the boundary layer between CB and IWBC. The results for this analysis showed that the behavior of both data is similar, showing a more superficial flow southwards, followed by a deeper flow northwards, demonstrating respectively the $B C$ and IWBC. The average depth of $B C$ was $300 \mathrm{~m}$ for MyOcean, while for HYCOM, it was $500 \mathrm{~m}$.

\section{CONCLUSIONS}

It can be seen that both data analyzed in the present study - from HYCOM and MyOcean database - showed a good concordance when compared. It should be noted, however, that the HYCOM didn't present a satisfactory analysis for IWBC, not being as efficient as MyOcean to solve the current in depth.

\section{REFERENCES}

Bleck, R. 2002. An oceanic general circulation model framed in Hybrid Isopycnic-Cartesian Coordinates. Ocean Modelling. 37(4): 55-88.

Fragoso, M. R. 2004. Um Modelo Numérico da Circulação Oceânica para as Bacias Leste e Sudeste do Brasil. Tese de Doutorado. COPPE - Universidade Federal do Rio de Janeiro. 173p.

Larnicol, G.; Guinehut, S.; Rio, M.; Drevillon, M.; Faugere, Y.; Nicolas, G. 2006. The Global Observed Ocean Products of the French Mercator Project. Proceedings of the 15 Years of progress in Radar Altimetry Symposium. ESA Special Publication. SP-614.

Lima, J. A. M. 1997. Ocean circulation on the Brazilian shelf break and continental slope at $22^{\circ} \mathrm{S}$. Tese de Doutorado. University of New South Wales. 164p.

Silveira, I. C. A. 2007. O Sistema Corrente do Brasil na Bacia de Campos, RJ. Tese de Doutorado. Universidade de São Paulo - USP. 160p.

Submetido: Julho/2013

Revisado: Abril/2016

Aceito: Março/2017 